UDC 316.334 .2

LBC 60.561.2

\title{
CREDIT CULTURE OF STUDENTS AS THE OBJECT OF SOCIOLOGICAL ANALYSIS
}

\author{
Nadezhda V. Dulina \\ Volgograd State University, Volgograd, Russian Federation \\ Dar'ja V. Moiseeva \\ Volgograd State Technical University, Volgograd, Russian Federation \\ Eugeniya V. Anufrieva \\ Volgograd State Technical University, Volgograd, Russian Federation \\ Vera A. Paramonova \\ Volgograd State University, Volgograd, Russian Federation
}

\begin{abstract}
Growth of volume in crediting to individuals in the Russian Federation during 2008-2018 and problems of debt maintenance have actualized the need of studying changes in the sphere of Russian crediting culture. The aim of the paper is to study credit attitude of modern student youth. At the first stage of the study the authors analyzed the correlation between key options: "credit culture", "credit attitude", "credit behavior", "financial culture", "financial attitude", "financial behavior". The investigators carried out the review of foreign and Russian research works aimed at studying the credit culture and credit behavior of students. They revealed features of foreign studies of credit culture / behavior, on this basis they conclude that this subject is poorly developed in Russia not only by individual socio-demographic groups, but also by the population generally. The working hypothesis of the research has been put forward: it is the change in the credit attitude of young people who do not have their own credit experience, which is the evidence of serious changes in the credit culture. At the second stage, the pilot study "Credit behavior of the population" (December 2017 - January 2018, Volgograd, accidental sampling $(n=404)$, the sample representation task was not set, the method of collecting information: on-line questioning) has been implemented. The results of the study let the authors to describe the credit culture of Volgograd Universities' students. The strong savings orientation among students has been defined. They are prone to saving money in a difficult situation and are ready to provide financial assistance, but they would not like to resort to it themselves in case of difficulties. Students realize the need of improving their level of financial literacy for building their own effective financial strategies. In the minds of students there is a necessity to correlate risk and result, but not all of them are ready to risk. Analysis of differences $\hat{q}$ in the responses of full-time and extra-mural students has confirmed the working hypothesis. Credit attitude of students, in our point of view, testify the rootedness of the youth credit culture. The correlation between the results of estimating the impact of credit practice on credit culture and the modern scale of crediting to Russians makes it possible to hypothesize that there will be a strong transformation of the credit culture of Russians in the next 20 years. The authors plan to test this hypothesis in their further studies.
\end{abstract}

Key words: credit culture, credit behavior, credit attitudes, economic behavior, financial behavior, gender a aspect, students.

\section{КРЕДИТНАЯ КУЛЬТУРА СТУДЕНТОВ КАК ОБЪЕКТ СОЦИОЛОГИЧЕСКОГО АНАЛИЗА}

\author{
Надежда Васильевна Дулина
}

Волгоградский государственный университет, г. Волгоград, Российская Федерация 


\title{
Дарья Викторовна Моисеева
}

Волгоградский государственный технический университет, г. Волгоград, Российская Федерация

\section{Евгения Владимировна Ануфриева}

Волгоградский государственный технический университет, г. Волгоград, Российская Федерация

\section{Вера Александровна Парамонова}

Волгоградский государственный университет, г. Волгоград, Российская Федерация

\begin{abstract}
Аннотация. Рост объемов кредитования физических лиц на территории Российской Федерации на протяжении 2008-2018 гг. и проблемы обслуживания задолженности актуализировали необходимость изучения изменений кредитной культуры россиян. Целью данной работы было определено изучение кредитных установок современной студенческой молодежи. На первом этапе исследования был выполнен анализ взаимосвязей основных понятий: ««кредитная культура», «кредитные установки», кредитное поведение», «финансовая культура», «финансовые установки», «финансовое поведение». Выполнен обзор зарубежных и российских исследований, направленных на изучение кредитной культуры и кредитного поведения студентов. Выявлены особенности зарубежных исследований кредитной культуры / поведения, сделан вывод о слабой разработанности данной тематики в России не только по отдельным социально-демографическим группам, но и в целом по населению. Выдвинута рабочая гипотеза исследования: именно изменение кредитных установок молодежи, не имеющих собственного опыта кредитования, является свидетельством серьезных изменений кредитной культуры. На втором этапе было реализовано зондажное исследование «Кредитное поведение населения» (декабрь 2017 г. - январь 2018 г., г. Волгоград, выборка стихийная $(n=404)$, задача репрезентации выборки не ставилась, метод сбора информации: on-line анкетирование). Результаты исследования позволили охарактеризовать кредитную культуру студентов волгоградских вузов. Среди студентов сильна ориентация на сбережения. Они склонны к экономии денежных средств в сложной ситуации и готовы оказать финансовую помощь, но сами не хотели бы к ней прибегать при возникновении трудностей. Студенты осознают необходимость повышения своей финансовой грамотности для выстраивания собственных эффективных финансовых стратегий. В сознании студентов выражена установка необходимости соотнесения риска / результата, далеко не все из них готовы рискнуть. Анализ различий в ответах студентов очной и заочной формы позволил подтвердить рабочую гипотезу. Кредитные установки студентов, по нашему мнению, свидетельствуют об укорененности кредитной культуры молодежи. Соотнесение результатов оценки влияния кредитной практики на кредитную культуру и современных масштабов кредитования россиян позволяет выдвинуть гипотезу о том, что в ближайшие 20 лет произойдет сильная трансформация кредитной культуры россиян. Данную гипотезу авторы планируют проверить в своих последующих исследованиях.

Ключевые слова: кредитная культура, кредитное поведение, кредитные установки, экономическое поведение, финансовое поведение, гендерный аспект, студенты.
\end{abstract}

\section{Введение}

Выход из экономического кризиса 20142016 гг. ознаменовался «взлетом» объемов кредитования физических лиц: за 2016 г. прирост кредитов, выданных физическим лицам, составил $23 \%$, за 2017 год - $28 \%$; сопоставление данных на сентябрь 2017 г. и 2018 г. показывает прирост в $40 \%$ [Сведения... web]. Несмотря на снижение доли просроченной задолженности с 8, 1 \% на 01.01.2016 до 7 \% на 01.01.2018 (в период между кризисами на 01.01.2013 данный показатель составлял 4,1 \%) [Сведения... web], данная тенденция вызывает серьезную озабоченность экспертов, которые характери- зуют сложившуюся ситуацию как «новый кредитный бум» [Грозовский web; Долг платежом классен... web; Ениколопов web; Натитник web; Соловьева web]. Характеризуя развитие этого явления, специалисты выделяют два важных, по нашему мнению, момента: 1) «жизнь в кредит» входит в привычку россиян [Грозовский web; Долг платежом классен... web; Соловьева web] и 2) молодежь вовлекается в кредитование активнее, чем другие возрастные группы [Кредитное поведение россиян... web; Фомченков web]. Оба эти факта позволяют поставить вопрос об изменении кредитной культуры россиян. В свете разворачивающейся под руководством Правительства России работы по 
повышению финансовой грамотности населения [Распоряжение Правительства РФ от 25.09.2017... web; Содействие повышению уровня... web] изучение процессов трансформации кредитной культуры как части финансовой культуры приобретает особую актуальность. Одним из факторов, повлиявших на принятие «Стратегии повышения финансовой грамотности в Российской Федерации на 20172023 гг.», стал рост просроченной задолженности россиян и недостаточно ответственное декларируемое отношение к обслуживанию долгов, зафиксированное в ходе социологических исследований [Распоряжение Правительства РФ от 25.09.2017 ... web]. Можно предположить, что, во-первых, в силу широкой распространенности и доступности кредитования физических лиц, во-вторых, кардинальных изменений институциональных условий этого процесса в результате смены условий хозяйствования, произошедших в нашей стране на рубеже 90-х годов прошлого века, кредитная культура обновляется с большей скоростью, чем сберегательная культура или культура инвестирования. На современном этапе важно зафиксировать основные параметры кредитной культуры, чтобы с течением времени иметь возможность оценить масштабы ее трансформации. Объектом проведенного исследования стали кредитные установки как часть кредитной культуры и фактор, влияющий на кредитное поведение населения. Предметом исследования были выбраны кредитные установки студенческой молодежи г. Волгограда. В качестве рабочей гипотезы исследования было сформулировано следующее утверждение: «именно изменение кредитных установок молодежи, не имеющих соб- ственного опыта кредитования, является свидетельством серьезных изменений кредитной культуры». Целью данной работы было определено изучение кредитных установок современной студенческой молодежи. Для достижения указанной цели были поставлены и решены следующие задачи: 1) анализ опыта исследований кредитной культуры и кредитного поведения студентов в России и за рубежом; 2) выбор и обоснование инструментария исследования; 3) проведение зондажного социологического исследования и анализ его результатов. В качестве методологической базы был выбран экономико-социологический подход.

\section{Основные понятия и их взаимосвязь}

Финансовое поведение население сравнительно недавно стало объектом исследования как экономистов, так и социологов, поэтому редко встречаются устоявшиеся определения даже базовых понятий. В связи с этим мы посчитали необходимым уточнить основные понятия, которые использовались в нашем исследовании, и охарактеризовать их соотношения между собой. Итак, «кредитное поведение», «кредитная культура», «кредитные установки», «финансовое поведение», «финансовая культура», «кредитный опыт» (см. рисунок).

Наиболее общим и широким из представленных понятий является понятие «финансовая культура». При его определении мы присоединяемся к мнению А.И. Фатихова и Р.Т. Насибуллина. Указанные авторы полагают, что «финансовая культура населения - это совокупность традиций, норм и идей, отражающих

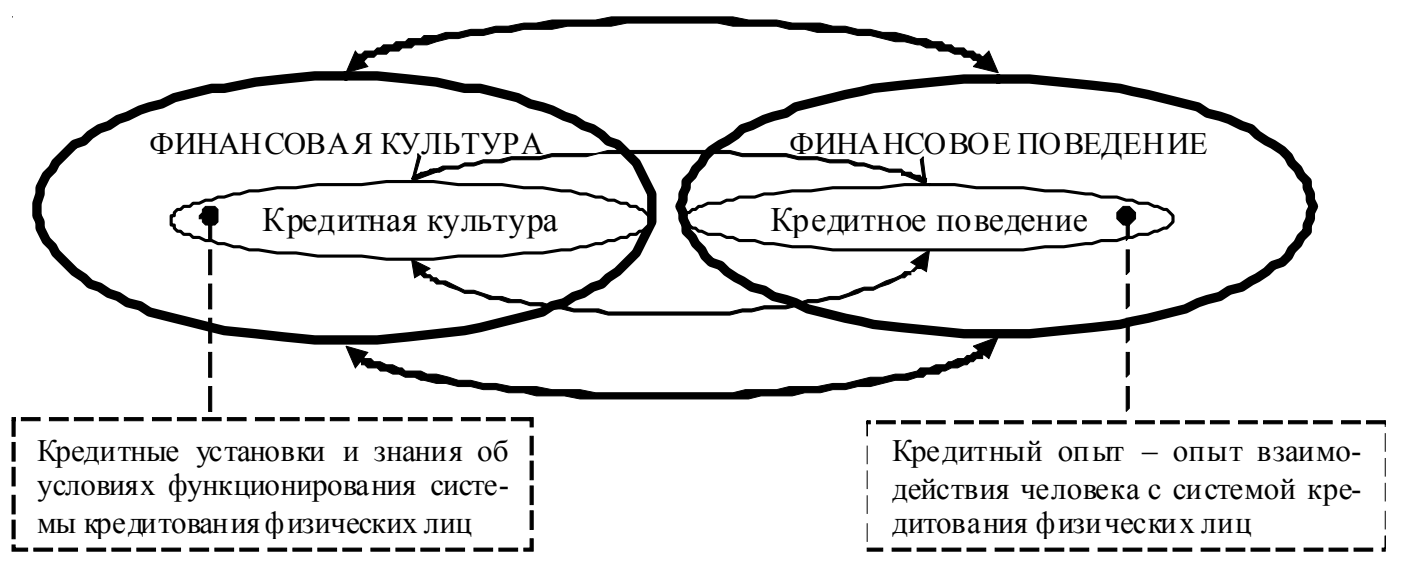

Основные понятия исследования и их взаимосвязь 
уровень финансовой грамотности, навыки и поведение людей в области финансовых отношений, финансового планирования и распределения денежных средств при существующем уровне развития в обществе инфраструктуры рынка, финансовых институтов и различных ценностей финансовой сферы, имеющих материальное воплощение и созданных целенаправленным воздействием людей» [Фатихов, Насибуллин 2010, 236]. Финансовое поведение также трактуется исследователями поразному. На наш взгляд, наиболее краткое и емкое определение дано Т.Ю. Богомоловой и В.С. Тапилиной: «Под финансовым поведением в широком смысле понимается поведение домохозяйств или индивидов, связанное с получением и расходованием денежных средств. ...сбережение, инвестирование, кредитование, страхование» [Богомолова, Тапилина 1998, 5859]. Финансовая культура определяет когнитивный и ценностно-мотивационный компоненты и является внешне заданной, определяемой в большей степени внешней средой, а финансовое поведение - это деятельностный компонент, то есть степень активности самого человека.

Исходя из представленных понятий, становится понятно, что кредитное поведение - это элемент финансового поведения, определяющий опыт взаимодействия человека с системой кредитования физических лиц. Д.О. Стребков дает следующее определение: «под кредитным (заемным) поведением мы будем понимать такую деятельность индивида или домохозяйства, в процессе которой происходит заимствование денежных средств, предполагающее их обязательное последующее возвращение» [Стребков 2004, 111]. В данном определении между заемным и кредитным поведением не проводится различий, однако необходимо подчеркнуть, что разница есть: заемное поведение шире, чем кредитное, оно включает в себя и практики неформального кредитования, то есть одалживания в долг у знакомых под проценты или без них, кредитное поведение - это вступление во взаимодействие с институтом кредита: обращение в кредитную организацию, обязательное заключение договора заимствования денежных средств с последующим обязательным возвратом.
Кредитную культуру также необходимо рассматривать как элемент целого - финансовой культуры. И.К. Ключников, О.А. Молчанова под кредитной культурой понимают «своеобразный сплав особого поведения и нравственного состояния общества, определяемого кредитом, она объясняет участие кредита в формировании не только основ жизнедеятельности, но и культурных потребностей человека, а также определяет механизм включения кредита в состав социально-культурного достояния современной личности» [Ключников, Молчанова 2011, 11]. Это определение подчеркивает тесную связь между кредитной культурой и кредитным поведением: приобретение опыта кредитования влечет за собой появление новых знаний о функционировании кредита и изменение отношения к нему, то есть формирует определенную кредитную культуру; новый уровень кредитной культуры, в свою очередь, начинает влиять на дальнейшее кредитное поведение человека. В другом определении, также представленном в работе И.К. Ключникова, О.А. Молчановой, подчеркивается, что кредитная культура - это «созданное и накопленное человечеством восприятие кредита, которое характеризует общее отношение к нему» [Ключников, Молчанова 2011, 13]. Отношение к кредиту фиксируется исследователями через кредитные установки, которые можно определить как предрасположение индивида и группы определенным образом реагировать на те или иные явления кредитной сферы. Несмотря на широкое распространение практик кредитования среди россиян, российскими учеными накоплен небольшой опыт исследования кредитного поведения, еще реже публикуются работы, посвященные изучению отношения к кредиту (кредитным установкам). Крайне редко встречаются исследования кредитных установок студенческой молодежи.

\section{Исследование \\ кредитного поведения и культуры: обзор зарубежных и российских исследований}

Исследования кредитной культуры и поведения студенческой молодежи чаще встре- 
чается в работах зарубежных авторов. В первую очередь это обусловлено системой кредитования образования, принятой во многих зарубежных странах. Так, например, в США за обучение платят в первую очередь студенты - сами или при помощи кредитных организаций, а во вторую - государство [Baсильцов, Левашов 2013]; возникающие сложности с обслуживанием образовательных кредитов студентами и становятся предметом исследований.

В работе R. Darolia и C. Harper описываются результаты эксперимента по использованию так называемых долговых писем, все более популярной стратегии предоставления легкодоступной информации о студенческих кредитах. Исследователи приходят к выводу о том, что одной информации недостаточно для изменения вариантов заимствования у учащихся [Darolia, Harper 2018]. S. Min и M.G. Taylor выполнили оценку роли студенческих кредитов в формировании будущих демографических моделей и поведения и пришли к выводу о влиянии на этот процесс задолженности по студенческим кредитам [Min, Taylor 2018]. D. Perkins, T. Johnston и R. Lytle обосновали необходимость реализации образовательных программ о кредитовании в школе с целью улучшения понимания студентами последствий задолженности и необходимости осторожности при финансировании их образования [Perkins, Johnston, Lytle 2016]. W. Elliott и M. Lewis в своем исследовании обратились к изучению влияния задолженности студентов на финансовые результаты студентов после окончания колледжа. Подобная оценка студенческих кредитов позволила им обосновать важность рассмотрения альтернативных подходов к финансированию высшего образования [Elliott, Lewis 2015]. W. Bosshardt и W.B. Walstad изучали особенности долгового поведения выпускников колледжа по экономическим и неэкономическим направлениям [Bosshardt, Walstad 2018].

Иной подход к исследованию кредитного поведения представлен в работе A.A. Adzis, J.A. Bakar и H.K. Shahar. Эти исследователи рассматривали факторы, влияющие на уровень задолженности молодых людей в Малайзии. Они подчеркивают негативное влияние рекламных предложений о кредитовании, ши- роко представленных в СМИ, и обосновывают необходимость разработки государственной политики, направленной на поддержку молодого поколения, которое легко может оказаться в состоянии чрезмерной задолженности, что, как следствие, приведет к его финансовой несостоятельности [Adzis, Bakar, Shahar 2017].

Результатом исследования, выполненного D. Wulandari, стал вывод о том, что зачастую причиной чрезмерного заимствования становятся психологические проблемы, такие как одиночество, низкая самооценка, стресс, давление со стороны сверстников и влияние социальных сетей. Исследователь считает, что программы повышения экономической и финансовой грамотности для студентов могут оказать положительное влияние на ситуацию [Wulandari 2016]. В работе A.J. Williams и B. Oumlil отмечено, что высокий уровень задолженности студентов тормозит экономический рост, и предложена модель повышения финансовой грамотности студентов колледжей, чтобы частично облегчить некоторые из проблем, связанных с дефицитом финансовых знаний среди этой группы населения [Williams, Oumlil 2015].

Исследователи S. Singh, D.H. Rylander и T.C. Mims изучили механизмы, влияющие на отношение студентов колледжа к компаниям, предлагающим кредитные карты, и поведение, которое студенты демонстрируют с помощью кредитных карт. Используя данные опроса, они выявили сильную положительную связь между отношением студентов к кредитным компаниям и ответственным кредитным поведением. Переменными в их анализе были: поведение при оплате кредитными картами, количество кредитных карт, способы приобретения, осведомленность об условиях по кредитным картам, цель использования кредитных карт, импульсивность и некоторые характеристики студентов [Singh, Rylander, Mims 2016].

В работе Jill M. Norvilitis представлен анализ изменений задолженности студентов колледжа и владения кредитными картами, а также отношения к долгам и кредитным картам за 10 лет в одном из кампусов американского колледжа. Автор отмечает, что после принятия в 2009 г. закона «О кредитных кар- 
тах» количество кредитных карт, размер выплат по кредитам и сумма задолженности по кредитным картам сократились. Отношение к долгу постепенно становилось все более негативным, в то время как воспринимаемое личное финансовое благополучие повышалось. Исследователь считает, что отношения студентов с кредитными картами меняются, но многие из них по-прежнему испытывают трудности с управлением кредитами [Norvilitis 2014]. Ранеe Jill M. Norvilitis совместно с Y. Мао провел межстрановое сравнение таких показателей, как финансовая уверенность в себе, воспринимаемое финансовое благополучие, отношение к долгу и родительское отношение к деньгам и долгам среди студентов из США и Китая [Norvilitis, Mao 2013].

Коллектив авторов под руководством Jill M. Norvilitis ранее выполнил исследование, позволившее выявить тесные зависимости между наличием задолженности по кредитам и таким факторам, как отсутствие финансовых знаний, возраст, количество кредитных карт, отсрочка вознаграждения и отношение к использованию кредитных карт. А вот склонность к риску, материализм, отношение студентов к долгу, пол и средний балл успеваемости не были уникальными предикторами долга [Norvilitis et al. 2006].

В статье J.A. Roberts и Е. Jones представлены результаты исследования взаимосвязей между установками в отношении денег и использования кредитных карт при компульсивных покупках на выборке студентов американских колледжей. Авторы отмечают, что изменение отношения к деньгам является важным катализатором распространения культуры потребления. Полученные ими данные свидетельствуют о том, что такие денежные установки, как власть престижа, недоверие и беспокойство, тесно связаны с совершением навязчивых покупок и что использование кредитных карт часто смягчает эти взаимосвязи [Roberts, Jones 2001].

Таким образом, можно выделить следующие особенности зарубежных исследований кредитного поведения и отношения к кредитам. Благодаря действующей во многих странах системе кредитования образования студенты этих стран раньше российских студентов принимают на себя кредитные обязательства. Функционированию этой системы и кредитно- му поведению студентов на рынке образовательных кредитов посвящен большой корпус исследований. Подобная проблематика не свойственна российской действительности.

Обратимся к опыту российских исследователей. Поиск в базе РИНЦ и базе Российской государственной библиотеки работ, посвященных кредитному поведению / культуре / установкам, фактически не дал результатов, найдена лишь одна работа С.Л. Ревзиной, описывающая результаты межрегионального социологического опроса, направленного на оценку знаний, умений и навыков пользования кредитами и кредитными картами российскими студентами. В итоге автор ставит проблему необходимости повышения уровня знаний студентов в финансовой сфере [Ревзина 2010]. В результатах поиска с использованием поисковых систем Яндекс и Гугл по тем же ключевым словам в основном представлены кредитные предложения для студентов и встретилось одно исследование. В этой статье на основе обзора рынка банковских услуг, предоставляемых учащимся, выполненного по заказу Бинбанка, дана краткая характеристика кредитного поведения, но технические параметры проведенного исследования непредставлены. Согласно сведениям, представленным в указанной работе, «85 \% студентов не пользуются кредитами, предпочитая дебетовые карты, денежные переводы и накопительные счета. < . . > По данным Бинбанка, среди российских студентов лишь $15 \%$ имеют кредиты, тогда как в целом по трудоспособному населению этот показатель составляет 54 \%. Нецелевыми потребительскими кредитами пользуются 5 \% студентов, а ипотекой и автокредитами - по 1,5\%. Основным кредитным банковским продуктом для студентов остается кредитная карта, ею пользуются 9 \% учащихся. В ряде случаев у одного студента может быть несколько кредитных продуктов. При этом в США, Канаде, Австралии, Новой Зеландии, а также в странах Европы студенты активно пользуются кредитами, в том числе займами на образование. Около 60 \% студентов за рубежом берут кредиты в банках. <..> Кредит на образование, согласно опросам, неактуален (для России. - Aвm.), так как зачастую у родителей имеются собственные накопления или вуз предлагает гибкую систему оплаты. В подавляющем большинстве случаев оплата образования 
происходит без привлечения заемных средств. В целом прослеживается установка, что лучше ужиматься в расходах, чем оформлять кредит на образование» [Алексеевских, Григорьева web]. Интересно мнение директора департамента международных финансовых отношений Минфина А. Бокарева, представленное там же: «Невысокая закредитованность студентов не является проблемой».

Отсутствие научных исследований по проблематике кредитного поведения и культуры студентов обосновало необходимость обращения к анализу работ, где объектом/ предметом исследования выбрана молодежь. Все найденные таким образом публикации написаны с участием студентов. В работах И.В. Поповой, И.М. Дудиной и В.С. Кругловой по результатам эмпирического исследования, направленного на изучение кредитного поведения молодежи г. Ярославля, выдвинута гипотеза взаимосвязи кредитного поведения и демонстративного потребления. Как дополнение к основной анкете по кредитному поведению авторы при проведении исследования использовали тест на определение индивидуальных ценностей, разработанный Ш. Шварцем [Дудина, Круглова 2016; Попова, Дудина 2018]. О.В. Киреева, А.Н. Дёмин, И.А. Помазан выполнили психологический анализ кредитной активности как процесса социального обмена между кредитором и заемщиком. Для изучения отношения к кредитам у разных возрастных групп, в том числе и молодежи, авторами был разработан специальный инструментарий. Он позволил измерить когнитивный аспект отношения с помощью шкалы «Осведомленность», мотивационно-оценочный аспект с помощью шкалы «Мотивация взятия кредита», а также поведенческий компонент отношения с помощью шкалы «Стратегии поведения в ситуации персонального дефолта». Методологически исследование строилось на теории обмена [Киреева, Демин, Помазан 2016]. Работа К.Н. Короля построена на данных эмпирического исследования мотивации кредитного поведения молодежи г. Саратова [Король 2018].

Анализ публикаций, размещенных в базе РИНЦ, по ключевым словам «кредитное поведение» и «кредитная культура» позволил сделать вывод о слабой разработанности данной тематики не только по отдельным социально- демографическим группам, но и в целом по населению. Одними из самых ранних и наиболее цитируемых на сегодняшний день работ по социологическому анализу кредитного поведения - это работы Д.С. Стребкова, построенные на авторских исследования 2002-2004 гг. [Стребков, Грибова web; Стребков 2004; Стребков 2007а; Стребков 2007б]. Ситуацию начала 2000-х он характеризует как этап становления новой кредитной культуры [Стребков 2007б, 101]; отмечая низкую востребованность кредитов, он указывает, что «можно будет добиться приобщения к кредитным стратегиям широких слоев населения» при условии укоренения в сознании людей ощущения стабильности [Стребков 2007б, 101]. В 2018 г. как данные ЦБ РФ, так и результаты социологических исследований подтверждают, что вовлечение широких слоев населения в процессы кредитования осуществлено. Таким образом, на современном этапе нам представляется важным изучение изменений, произошедших в сознании населения по отношению к кредиту.

Среди авторов более поздних работ по социологическому анализу кредитного поведения и кредитной культуры можно выделить работы Е.А. Грибовой, Д.Х. Ибрагимовой [Грибова, Ибрагимова 2011; Ибрагимова 2011], А.А. Дикого [Дикий 2012а; Дикий 2012б], Г.В. Белеховой [Белехова 2014; Белехова 2015], Г.Б. Юдина [Юдин 2015].

Подводя итог обзору зарубежных и российских исследований кредитного поведения и культуры, хотелось бы отметить следующие моменты: 1) в практике российских исследований обращение к студентам как целевой группе встречается крайне редко; 2) и в зарубежных, и в российских исследованиях инструментарий включает вопросы, направленные на изучение и кредитного опыта, и кредитных установок (кредитной культуры).

\section{Методика \\ социологического исследования}

С целью изучения кредитного поведения и культуры современной студенческой молодежи авторами было проведено социологическое исследование «Кредитное поведение населения», которое имеет следующие технические параметры: 
- срок проведения: декабрь 2017 г. - январь 2018 г.;

- территория исследования: г. Волгоград;

- к опросу были приглашены студенты двух вузов, это-Волгоградский государственный технический университет (ВолгГТУ) и Волгоградский государственный университет (ВолГУ);

- общее число опрошенных - 442 чел.

В результате визуального контроля качества поступивших анкет для обработки было отобрано 404 анкеты $(n=404)$, в том числе в ВолгГТУ - 334 анкет, ВолГУ - 70 анкет;

- выборка стихийная; задача репрезентации выборки не ставилась;

- метод сбора информации: on-line анкетирование: анкета распространялась через преподавателей, почтовые ящики групп, группы студентов в социальных сетях.

Соотношение респондентов по полу $57 \%$ / $43 \%$ мужчин и женщин соответственно, по форме обучения - $65 \%$ / 35 \% студентов очных отделений и заочных отделений соответственно, 80 \% студентов младших курсов.

\section{Результаты исследования}

Подчеркнем, что исследование носило зондажный характер и распространить его результаты для характеристики кредитного поведения всех волгоградских студентов невозможно, однако полученные данные позволили понять суть происходящих процессов, оценить существующие взаимосвязи внутри выборки, выдвинуть гипотезы для дальнейших исследований, а также скорректировать разработанный инструментарий.

Самооценка материального положения у студентов очного и заочного отделения практически не отличается: большинство (59\%) указало, что денег достаточно для приобретения необходимых продуктов и одежды, более крупные покупки приходится откладывать (61\% и $59 \%$ очников и заочников соответственно). Среди студентов, принявших участие в нашем опросе, половина (55 \%) указали, что ни лично они, ни их семья за последние два года ничего не приобретали в кредит. Среди очников такой ответ встречается чаше (65\% и $39 \%$ очников и заочников соответственно). Исходя из этого, была выдвинута гипотеза, что кредитные установки студентов очного отде- ления, практически не имеющих собственного опыта кредитования, в большей степени определяются кредитной культурой семьи, в которой они выросли, а кредитная культура студентов-заочников, зачастую уже самостоятельно решающих повседневные финансовые вопросы, трансформирована личным кредитным опытом. Соответственно, анализ различий в установках студентов очного и заочных отделений позволит прояснить, как изменяется отношение людей к кредиту при необходимости самостоятельно формировать и реализовывать стратегии финансового поведения.

В исследовании были использованы формулировки утверждений, позволяющих дать характеристику кредитным установкам, разработанные Д.С. Стребковым и Е.А. Грибовой [Стребков, Грибова web]. Ими были выделены такие факторы, как: отношение к получению денег в долг, отношение к предоставлению денег в долг, отношение к кредиту как к социальному явлению, отношение к сбережениям, отношение к деньгам и богатству, склонность к риску, стремление к росту благосостояния. Для оценки степени согласия или несогласия с предложенными респондентам высказываниями использовалась пятибалльная шкала, где: 1 - совсем не согласен, 2 скорее не согласен, 3 - затрудняюсь ответить, 4 - скорее согласен, 5 - полностью согласен. Для оценки силы установки была использована следующая методика:

1. По каждому из утверждений рассчитываются распределения ответов респондентов (доли ответов, приходящихся на каждую из категорий представленной шкалы).

2. Каждое из полученных распределений используется для построения частного индекса, который рассчитывается следующим образом: из доли положительных ответов вычитается доля отрицательных (средние и несодержательные варианты ответов не учитываются), и к этой разнице прибавляется 100, чтобы исключить появление отрицательных величин. Значения индекса могут изменяться в пределах от 0 до 200. Индекс равен 200, когда все респонденты положительно оценивают экономическую ситуацию. Индекс равен 100, когда доля положительных и отрицательных оценок одинакова. Значения индекса ниже 100 означают преобладание в совокупности опрошенных негативных оценок. 

таблице.

Результаты расчетов представлены в

Анализ полученных значений индексов позволил выявить установки с высокой степенью согласия / несогласия, выделить различия по двум признакам (форма обучения и пол).

Так получилось, что при изучении кредитной культуры студентов наибольшую степень согласия получило утверждение, касающееся необходимости создания сбережений. Этот факт совпадает с оценками студентами внешней среды для создания сбережений и кредитов. В ответах на вопросы «Как Вы считаете, сейчас хорошее или плохое время для того, чтобы делать сбережения / брать кредиты?» по сбережениям преобладают положительные оценки (52 \% оценивают время как определенно хорошее / пожалуй, хорошее), а по кредитам - негативные (50 \% оценивают время как определенно плохое / пожалуй, плохое). При этом ориентация на приоритет сбережений («сбережения нужно делать обязательно, пусть даже и отказывая себе в самом необходимом») получила нейтральную оценку, а предположение о бессмысленности совершения сбережений в современных условиях - негативную («сберегать деньги сейчас не имеет смысла - все равно они обесцениваются в результате инфляции, и нет никакой гарантии их сохранности»). Таким образом, сбережения как стратегия финансового поведения имеет положительные оценки.

Студенты отмечают неготовность брать в долг большие суммы денег. Самая высокая степень несогласия выявлена по утверждению, что люди, которые живут в кредит, являются более расчетливыми, они умеют считать деньги, у них есть уверенность в завтрашнем дне. Кроме того, сильна ориентация на то, что при возникновении финансовых затруднений целесообразнее экономить, а не заимствовать. Сопоставление данных результатов с ответами на вопрос о том, в каких случаях респонденты готовы обращаться за кредитом в финансовую организацию (когда наиболее часто указывались такие цели, как сложная жизненная ситуация (35\%) и приобретение недвижимости (33\%)), позволяет сделать вывод, что кредит не рассматривается как повседневная финансовая стратегия (стратегия управления текущими доходами и расходами).

Неожиданно высокую степень согласия получили утверждения, касающиеся необходи- мости повышения финансовой грамотности детей со школьной скамьи и самостоятельного обеспечения собственной старости. Следовательно, на проект повышения финансовой грамотности населения, реализуемый при поддержке Правительства России [Распоряжение Правительства РФ от 25.09.2017 ... web; Содействие повышению уровня... web], существует социальный запрос, и студенты заинтересованы в его реализации.

Анализ отношения к заимствованию денег выявил одобрение предоставления денег в долг в качестве помощи близким людям, но неготовность обращаться за подобной помощью. В аналогичным выводам по отношению к россиянам в целом в своем исследовании приходит Г.Б. Юдин: «Закредитованность во многом связана со склонностью полагаться только на себя и нежеланием искать совета и поддержки. <...> Люди берут кредит, чтобы не брать в долг: они боятся попасть в зависимость от близкого человека и тем самым разрушить с ним отношения и оказаться в психологически подчиненном состоянии» [Натитник web]. На вопрос о том, кто лучше защищен от деструктивных последствий кредитных отношений, он отвечает следующее: «Лучше всего защищены те, кто не избегает коммуникации, - кто умеет дружить, выстраивать партнерские отношения и является членом каких-либо плотных коллективов. Надо окружать себя людьми, с которыми можешь о чем-то договариваться, советоваться, нужно встраиваться в сообщества, в которых можешь кому-то помогать и пользоваться помощью - как моральной, так и материальной» [Натитник web].

В оценке склонности к риску наблюдается диссонанс. С одной стороны, высокая степень несогласия с утверждением «При необходимости я могу рискнуть и потратить "все, что у меня есть” (индекс равен $58 \%$ ); с другой - значительная степень одобрения тезиса «Я готов пожертвовать своим благосостоянием сегодня ради того, чтобы добиться значительного успеха в будущем» (индекс равен $128 \%$ ). Можно предположить, что сильна установка необходимости соотнесения риска / результата: пожертвовать собственным благосостоянием (то есть не слишком многим, учитывая материальное положение и положение в обществе современных студентов), но не рискнуть всем. 


\section{Индексы кредитных установок, \%}

\begin{tabular}{|c|c|c|c|c|c|}
\hline \multirow{2}{*}{ Формулировка утверждения } & \multirow{2}{*}{$\begin{array}{c}\text { В целом } \\
\text { по массиву }\end{array}$} & \multicolumn{2}{|c|}{ Форма обучения } & \multicolumn{2}{|c|}{ Пол респондента } \\
\hline & & очная & заочная & женский & мужской \\
\hline $\begin{array}{l}\text { Сбережения необходимы любой семье, чтобы иметь уве- } \\
\text { ренность в завтрашнем дне }\end{array}$ & 176 & 176 & 178 & 178 & 175 \\
\hline Я бы не стал брать в долг крупную сумму денег & 168 & 173 & 160 & 166 & 170 \\
\hline $\begin{array}{l}\text { Даже если мне придется тяжело, я буду экономить, но за- } \\
\text { лезать в долги не стану }\end{array}$ & 167 & 176 & 149 & 156 & 174 \\
\hline $\begin{array}{l}\text { Детей уже в школе следует приучать быть бережливыми, } \\
\text { создавать свой капитал }\end{array}$ & 163 & 161 & 168 & 166 & 161 \\
\hline $\begin{array}{l}\text { Каждый сам должен позаботиться о своей старости, а не } \\
\text { рассчитывать только на государство }\end{array}$ & 155 & 150 & 166 & 153 & 157 \\
\hline $\begin{array}{l}\text { Если у меня есть свободные деньги - я легко дам в долг на- } \\
\text { дежному человеку: сегодня ты помог, завтра тебе помогут }\end{array}$ & 152 & 148 & 159 & 141 & 160 \\
\hline $\begin{array}{l}\text { Деньги должны «работать», поэтому следует стараться вкла- } \\
\text { дывать их в различные активы, приносящие прибыль }\end{array}$ & 150 & 152 & 149 & 144 & 155 \\
\hline $\begin{array}{l}\text { Человек, взявший кредит, будет стараться более активно } \\
\text { работать, чтобы скорее погасить его }\end{array}$ & 139 & 139 & 139 & 148 & 132 \\
\hline $\begin{array}{l}\text { Все в нашей жизни сейчас зависит от денег. Если есть } \\
\text { деньги, то все остальное приложится }\end{array}$ & 134 & 129 & 143 & 138 & 131 \\
\hline $\begin{array}{l}\text { Я готов пожертвовать своим благосостоянием сегодня ради } \\
\text { того, чтобы добиться значительного успеха в будущем }\end{array}$ & 128 & 128 & 128 & 110 & 128 \\
\hline $\begin{array}{l}\text { Мои родители были бережливыми людьми, они старались } \\
\text { экономить каждую копейку }\end{array}$ & 120 & 116 & 129 & 115 & 110 \\
\hline $\begin{array}{l}\text { Благодаря кредитам люди по купают больше товаров, а это, } \\
\text { в свою очередь, способствует росту производства }\end{array}$ & 112 & 106 & 124 & 105 & 117 \\
\hline $\begin{array}{l}\text { Одалживать деньги другим намного проще и приятнее, } \\
\text { нежели просить их самому }\end{array}$ & 112 & 106 & 121 & 109 & 97 \\
\hline $\begin{array}{l}\text { Когда я был ребенком, мои родители практически ни в чем } \\
\text { мне не отказывали, у меня всегда было достаточно денег } \\
\text { на карманные расходы }\end{array}$ & 102 & 107 & 94 & 101 & 100 \\
\hline $\begin{array}{l}\text { Сбережения нужно делать обязательно, пусть даже и отка- } \\
\text { зывая себе в самом необходимом }\end{array}$ & 101 & 100 & 101 & 98 & 102 \\
\hline $\begin{array}{l}\text { Возможность купить необходимую вещь в кредит позволяет } \\
\text { человеку планировать свою жизнь на несколько лет вперед }\end{array}$ & 100 & 93 & 115 & 93 & 100 \\
\hline $\begin{array}{l}\text { Ожидая возвращения долга, всегда беспокоишься, даже } \\
\text { если должником является хороший друг }\end{array}$ & 97 & 97 & 96 & 85 & 96 \\
\hline Богатыми могут стать только бережливые и экономные люди & 91 & 86 & 102 & 74 & 98 \\
\hline Я стараюсь по возможности никому не давать деньги в долг & 84 & 83 & 87 & 69 & 96 \\
\hline $\begin{array}{l}\text { Деньги портят человека, поэтому среди бедных больше } \\
\text { порядочных людей, чем среди богатых }\end{array}$ & 84 & 79 & 93 & 76 & 90 \\
\hline $\begin{array}{l}\text { В долги залезают чаще всего бездельники и те люди, кто } \\
\text { не может позаботиться о себе }\end{array}$ & 78 & 84 & 67 & 66 & 88 \\
\hline $\begin{array}{l}\text { В настоящее время кредит в банке могут взять только со- } \\
\text { стоятельные граждане }\end{array}$ & 73 & 81 & 57 & 63 & 80 \\
\hline $\begin{array}{l}\text { Деньги в долг берут те люди, кто хочет жить лучше, чем } \\
\text { может на самом деле }\end{array}$ & 72 & 74 & 69 & 64 & 78 \\
\hline $\begin{array}{l}\text { Сберегать деньги сейчас не имеет смысла - все равно они } \\
\text { обесцениваются в результате инфл яции, и нет никакой га- } \\
\text { рантии их сохранности }\end{array}$ & 69 & 70 & 67 & 70 & 69 \\
\hline $\begin{array}{l}\text { Меня сильно раздражает, когда кто-либо просит у меня } \\
\text { деньги в долг }\end{array}$ & 69 & 68 & 70 & 61 & 75 \\
\hline $\begin{array}{l}\text { При необходимости я могу рискнуть и потратить «все, что } \\
\text { у меня есть» }\end{array}$ & 58 & 53 & 69 & 56 & 60 \\
\hline $\begin{array}{l}\text { Я часто совершаю спонтанные покупки и приобретаю ве- } \\
\text { щи, которые мне, в принципе, не нужны }\end{array}$ & 58 & 58 & 59 & 67 & 51 \\
\hline $\begin{array}{l}\text { Я никогда не стесняюсь просить у друзей и знакомых } \\
\text { деньги в долг }\end{array}$ & 55 & 52 & 59 & 49 & 59 \\
\hline $\begin{array}{l}\text { Люди, которые живут в кредит, являются более расчетли- } \\
\text { выми, они умеют считать деньги, у них есть уверенность в } \\
\text { завтрашнем дне }\end{array}$ & 54 & 48 & 66 & 50 & 57 \\
\hline
\end{tabular}

Примечание. Курсивом выделены значения индексов, разница по которым внутри признака составляет от 10 до $19 \%$; выделение жирным использовано для индексов, разница по которым внутри признака составляет свыше $20 \%$. 
Положительно можно оценить высокую степень несогласия с утверждением «Я часто совершаю спонтанные покупки и приобретаю вещи, которые мне, в принципе, не нужны», то есть на уровне установок шопоголизм и навязчивые, необдуманные покупки не одобряются, они несвойственны студентам.

Анализ различий в оценках студентов очного и заочного отделений показал, что среди очников гораздо выше одобрение стратегии экономии при возникновении финансовых сложностей и избегания заимствования, чем среди заочников. Молодежь, еще не вступившая полностью в самостоятельную жизнь, считает, что без долгов можно обойтись. Те же, кто начал самостоятельную жизнь, понимают, что это не всегда возможно. «Начинающие взрослые» не осознают взаимосвязи между кредитными практиками и финансовой дисциплиной, а люди, уже прибегавшие к кредитам, знают, что одно без другого приводит к печальным последствиям (это подтверждается оценкой двух утверждений). Аналогичные различия зафиксированы в понимании условий предоставления кредитов: среди заочников больше тех, кто понимает, что сегодня кредит могут получить люди любого достатка. Итак, все значимые различия (то есть разница в значениях индексов более 20 \%) наблюдаются только по установкам, связанным с отношением к кредиту. Данный факт подтверждает нашу гипотезу о влиянии реальной кредитной практики на представления студентов о кредитах.

Также косвенным подтверждением нашей гипотезы стали гендерные различия кредитной культуры студентов. При оценке различий в ответах по полу, также как по форме обучения, зафиксировано четыре значимых (то есть разница в значениях индексов более $20 \%$ ), но их набор совсем другой и степень согласия мужчин выше, чем у женщин, но всем четырем утверждениям. Индексы по двум из этих утверждений фиксируют отношения к предоставлению / получению денег в долг: и мужчины, и женщины готовы оказать финансовую помощь надежному человеку, но женщины менее одобрительно относятся к подобным действиям, однако их ответы говорят, что они реже уклоняются от этой практики. Женщины менее склонны связывать безделье и долги (значение индексов у мужчин и женщин
$88 \%$ и $66 \%$ соответственно) и меньше согласны с утверждением, что богатыми могут стать только бережливые и экономные люди (значение индексов у мужчин и женщин 98 \% и $74 \%$ соответственно). Разницу в кредитных установках мужчин и женщин можно объяснить спецификой ментальности и укорененностью хозяйственных практик.

\section{Выводы и обсуждение результатов}

Выполненный анализ кредитной культуры студентов волгоградских вузов позволяет заключить, что:

1) в первую очередь студенты ориентированы на сбережение, осознают важность и необходимость данной финансовой практики;

2) среди студентов сильна установка на экономию финансов в сложной ситуации, а не решение проблем посредством заимствования;

3) они в большей степени ориентированы на оказание, чем на получение финансовой помощи в сложной ситуации;

4) осознают необходимость выстраивания собственных финансовых стратегий и готовы повышать финансовую грамотность;

5) у студентов выражена установка необходимости соотнесения риска / результата, они далеко не все готовы рискнуть;

6) студенты негативно относятся к фактам спонтанных / ненужных покупок.

Выявленные различия в ответах студентов очной и заочной формы позволили подтвердить гипотезу об изменении кредитной культуры под влиянием кредитной практики. Гендерные различия кредитных установок студентов косвенно также подтверждают выдвинутые гипотезы. Кредитные установки, зафиксированные в нашем исследовании, свидетельствуют об укорененности кредитной культуры молодежи: она действительно в большей степени отражает отношение к кредитам, переданное им старшим поколением. Однако, учитывая масштабы роста кредитной задолженности россиян, о которой говорилось в начале статьи, и выявленное влияние кредитной практики на кредитную культуру, серьезных изменений кредитной культуры можно ожидать уже у следующего поколения россиян. Социологам важно отслеживать происходящие изменения, поэтому надеемся, что данная ста- 
тья станет лишь звеном в цепи востребованных работ по изучению кредитного поведения и кредитной культуры российской молодежи, в том числе и студентов.

\section{СПИСОК ЛИТЕРАТУРЫ}

Алексеевских, Григорьева web - Алексеевских A., Григорьева И. Студенты против кредитов: российская молодежь предпочитает копить, а не тратить // https://iz.ru/news/720305.

Белехова 2014 - Белехова Г.В. Кредитное поведение населения: современные аспекты (на примере Волгоградской области) // Вопросы территориального развития. 2014. Вып. 1 (11). С. 2-14.

Белехова 2015 - Белехова Г. В. Социально-демографические особенности финансового поведения населения // Проблемы развития территории. 2015. № 1 (75). С. 100-115.

Богомолова, Тапилина 1998 - Богомолова Т.Ю., Тапилина В.С. Финансовое поведение домохозяйств в России в середине 90-х годов // Экономическая наука современной России. 1998. № 4. С. 58-69.

Васильцов, Левашов 2013 - Васильциов В.С., Левашов E.H. Система кредитования высшего образования в США // Вестник Череповецкого государственногоуниверситета. 2013. № 1 (54). С. 70-74.

Грибова, Ибрагимова 2011 - Грибова Е.А., Ибрагимова Д.Х. Установки населения относительно сбережений и кредитов // Вестник Российского мониторинга экономического положения и здоровья населения НИУ ВШЭ (RLMSHSE). 2011. С. 121-130.

Грозовский web - Грозовский Б. Как Россия идет к третьему кредитному кризису // https:// openmedia.io/exclusive/kak-rossiya-idet-ktretemu-kreditnomu-krizisu/.

Дикий 2012а - Дикий А.А. Жизнь в кредит: установки и поведенческие стратегии россиян // Социологические исследования. 2012. №5 (337). С. 134-140.

Дикий 2012б - Дикий А.А. Стратегии долгового поведения населения в современной России: дис. ... канд. социол. наук. Иваново, 2012.

Долг платежом классен... web - Долг платежом классен: чем закончится новый кредитный бум в России // https://ria.ru/economy/20171023/ 1507277589.html.

Дудина, Круглова 2016 - Дудина И.М., Круглова B.C. Обращение к кредитной практике как одна из интеграционных стратегий молодежи в сфере экономики // Инновационный потенциал молодежи: глобализация, политика, интеграция. Екатеринбург, 2016. С. 159-164.
Ениколопов web - Ениколопов Р. В России кредитный бум. Это хорошо или плохо? Может, мне тоже стоит взять кредит? // https://meduza.io/ cards/v-rossii-kreditnyy-bum-eto-horosho-iliploho-mozhet-mne-tozhe-stoit-vzyat-kredit.

Ибрагимова 2011 - Ибрагимова Д.Х. Установки россиян относительно сбережений и кредитов // Банковское дело. 2011. № 12. С. 74-80.

Киреева, Дёмин, Помазан 2016 - Киреева О.В., Дёмин А.Н., Помазан И.А. Мотивационный компонент отношения к кредитам лиц разного возраста // Политематический сетевой электронный научный журнал Кубанского государственного аграрного университета. 2016. № 123. С. 1049-1065.

Ключников, Молчанова 2011 - Ключников И.К., Молчанова О.А. Кредитная культура: сущность, закономерности, формы: учебное пособие. СПб.: Изд-во Санкт-Петербургского гос. ун-та экономики и финансов, 2011.

Король 2018 - Король К.Н. Кредитное поведение современной молодежи России // Вестник Саратовского государственного социально-экономического университета. 2018. № 1 (70). С. 144-146.

Кредитное поведение россиян... web - Кредитное поведение россиян различного возраста [Национальное бюро кредитных историй] // https:/ /www.nbki.ru/upload/pdf/2013_06_14_ kreditnoe_povedenie.pdf.

Натитник web-Натитник А. «Должниками проще управлять»: [интервью с автором исследования «Жизнь в долг» Г.Б. Юдиным] // https://hbr-russia.ru/biznes-i-obshchestvo/ fenomeny/778884.

Попова, Дудина 2018 - Попова И.В., Дудина И.М. Ценностный аспект кредитного поведения молодежи (опыт эмпирического исследования) // ЦИТИСЭ. 2018. № 1 (14). С. 19.

Распоряжение Правительства РФ от 25.09.2017... web - Распоряжение Правительства РФ от 25.09.2017 № 2039-р «Об утверждении Стратегии повышения финансовой грамотности в Российской Федерации на 2017-2023 гг.» // http://www.garant.ru/products/ipo/prime/doc/ 71675558/\#ixzz5NZ8nq1NU.

Ревзина 2010 - Ревзина С.Л. Знания студентов о кредитах и кредитных картах // Известия Саратовского университета. Новая серия. Серия: Социология. Политология. 2010. Т. 10, № 2. С. $46-48$.

Сведения... web - Сведения о размещенных и привлеченных средствах [Официальный сайт ЦБ PФ] // http://www.cbr.ru/statistics/?PrtId=sors.

Содействие повышению уровня... web - Cодействие повышению уровня финансовой гра- 
мотности населения и развитию финансового образования в Российской Федераџи [Информация официального сайта Министерства финансов Российской Федерации] // https:/www.minfin.ru/ru/om/fingram/news/ \#ixzz5NZ6ZVgcP.

Соловьева web-Соловьева O. Россияне не любят кредиты, но жить без них не могуг // http://www.ng.ru/ economics/2018-09-30/4 7321 credit.html.

Стребков 2004 - Стребков Д.О. Основные типы и факторы кредитного поведения населения в современной России // Вопросы экономики. 2004. № 2. С. 109-128.

Стребков 2007a - Стребков Д.О. Модели кредитного поведения и факторы, определяющие их выбор // Социологические исследования. 2007. № 3 (275). С. 52-62.

Стребков 2007б - Стребков Д.О. Социальные аспекты кредитного поведения // Социологический журнал. 2007. № 1. С. 83-103.

Стребков, Грибова web - Стребков Д.О., Грибова E.A. Развитие системы кредитования в России: анализ потребностей и предпочтений населения // http://www.socpol.ru/grantprog/pdf/ Strebkov.pdf

Фатихов, Насибуллин 2010 - Фатихов А.И., Насибуллин Р.Т. Проблемы формирования финансовой культуры населения России сквозь призму социологических исследований // Вестник ТОГУ. 2010. № 2 (7). С. 235-244.

Фомченков web - Фомченков T. Берешь, молодежь! Количество кредитов у молодых людей растет быстрее, чем у людей других возрастов // https://rg.ru/2017/04/23/issledovanie-molodyeliudi-chashche-drugih-berut-kredity.html.

Юдин 2015 - Юдин Г.Б. Моральная природа долга и формирование ответственного заемщика // Вопросы экономики. 2015. № 3. С. 28-45.

Adzis, Bakar, Shahar 2017 -Adzis A.A., Bakar J.A., Shahar H.K. Factors influencing young adults' debt in Malaysia // Journal of Business and Retail Management Research. 2017. № 12 (1). P. 76-85.

Bosshardt, Walstad 2018-Bosshardt W., Walstad W.B. Does studying economics in college influence loan decisions later in life? // Journal of Economic Education. 2018. № 49 (2). P. 130-141. DOI: $10.1080 / 00220485.2018 .1438948$.

Darolia, Harper 2018 - Darolia R., Harper C. Information Use and Attention Deferment in College Student Loan Decisions: Evidence From a Debt Letter Experiment // Educational Evaluation and Policy Analysis. 2018. №40 (1). P. 129-150. DOI: 10.3102/ 0162373717734368.

Elliott, Lewis 2015 -Elliott W., Lewis M. Student debt effects on financial well-being: Research and policy implications // Journal of Economic Surveys. 2015. № 29 (4). P. 614-636.

Min, Taylor 2018 - Min S., Taylor M.G. Racial and Ethnic Variation in the Relationship Between Student Loan Debt and the Transition to First Birth // Demography. 2018. № 55 (1). P. 165-188. DOI: $10.1007 / \mathrm{s} 13524-017-0643-6$ 10.3102/ 0162373717709968.

Norvilitis 2014 -Norvilitis J.M. Changes over time in college student credit card attitudes and debt: evidence from one campus // The Journal of consumer affairs. 2014. Vol. 48, № 3. P. 634-647.

Norvilitis, Mao 2013 - Norvilitis J.M., Mao Y. Attitudes towards credit and finances among college students in China and the United States // International Journal of Psychology. 2013. Vol. 48, № 3. P. 389-398.

Norvilitis et al. 2006 - Norvilitis J.M. Merwin M.M., Osberg T.M., Roehling P.V., Young P., Kamas M.M. Personality Factors, Money Attitudes, Financial Knowledge, and Credit-Card Debt in College Students // Journal of Applied Social Psychology. 2006. Vol. 36, №6. P. 1395-1413.

Perkins, Johnston, Lytle 2016 - Perkins D., Johnston T., Lytle $R$. Addressing student debt in the classroom // Journal of Education for Business. 2016. № 91 (3). P. 117-124. DOI: 10.1080/ 08832323.2016.1140112.

Roberts, Jones 2001 -Roberts J.A., Jones E. Money Attitudes, Credit Card Use, and Compulsive Buying among American College Students // The Journal of Consumer Affairs. 2001. Vol. 35, № 21. P. 213-240.

Singh, Rylander, Mims 2016 - Singh S., Rylander D.H., Mims T.C. College students and credit card companies: Implications of attitudes // Journal of Financial Services Marketing. 2016. № 21 (3). P. 182-193. DOI: 10.1057/s41264-016-0007-0.

Williams, Oumlil 2015 - Williams A.J., Oumlil B. College student financial capability: A framework for public policy, research and managerial action for financial exclusion prevention // Marketing Intelligence and Planning. 2015. №33 (5). P. 637-653. DOI: 10.1108/ IJBM-06-2014-0081.

Wulandari 2016 - Wulandari D. Causes, effects and solutions of overspending behavior in university students // International Journal of Economic Research. 2016. № 13 (7). P. 3097-3110.

\section{REFERENCES}

Alekseevskih A., Grigor'eva I. Students vs loans: the Russian youth prefers to save money instead of spending. URL: https://iz.ru/news/720305 (accessed 15 September 2018). 
Belekhova G.V., 2014. Credit behavior of the population: modern aspects (on the example of the Vologda oblast). Voprosy territorial'nogo razvitiya, Iss. 1 (11), pp. 2-14.

Belehova G.V., 2015. Socio-demographic peculiarities of population's financial behavior. Problemy razvitija territorii, no. 1 (75), pp. 100-115.

Bogomolova T.Yu., Tapilina V.S., 1998. The financial behavior of households in Russia in the middle of the 90-ies. Ehkonomicheskaya nauka sovremennoj Rossii, no. 4, pp. 58-69.

Vasil'cov V.S., Levashov E.N., 2013. Credit System of higher education in the United States. Vestnik CHerepoveckogo gosudarstvennogo universiteta, no. 1 (54), pp. 70-74.

Gribova E.A., Ibragimova D.H., 2011. Attitudes of the population regarding the savings and loans. V sbornike: Vestnik Rossijskogo monitorin-ga ehkonomicheskogo polozheniya i zdorov'ya naseleniya NIUVSHEH (RLMS-HSE), pp. 121-130.

Grozovskij B. How Russia is going to the third credit crisis. URL: https://openmedia.io/exclusive/kakrossiya-idet-k-tretemu-kreditnomu-krizisu/ (accessed 1 September 2018).

DikijA.A., 2012. Life in the credit: install and behavioral strategies of Russians. Sociologicheskie issledovaniya, no. 5 (337), pp. 134-140.

Dikij A.A., 2012. The Strategy of the debt behavior of the population in modern Russia. Diss. candidate of sociological sciences. Ivanovo.

Debt payment class: what will end the new credit boom in Russia. URL: https://ria.ru/economy/ 20171023/1507277589.html (accessed 1 September 2018).

Dudina I.M., Kruglova V.S., 2016. Appeal to credit practice as one of the integration strategies of youth in the field of economy. Innovacionnyj potencial molodezhi: globalizaciya, politika, integraciya. Ekaterinburg, pp. 159-164.

Enikolopov R.V. In Russia credit boom. Is that good or bad? Maybe I should take the credit? URL: $\mathrm{https://meduza.io/cards/v-rossii-kreditnyy-bum-}$ eto-horosho-ili-ploho-mozhet-mne-tozhe-stoitvzyat-kredit (accessed 1 September 2018).

Ibragimova D.H., 2011. The Installation of Russians on the savings and credit. Bankovskoe delo, no. 12 , pp. $74-80$.

Kireeva O.V., Dyomin A.N., Pomazan I.A., 2016. Motivational component in relation to loans to individuals of different age. Politematicheskij setevoj ehlektronnyj nauchnyj zhurnal Kubanskogo gosudarstvennogo agrarnogo universiteta, no. 123, pp. 1049-1065.

Klyuchnikov I.K., Molchanova O.A., 2011. Credit culture: the nature, laws, forms: textbook. Saint Petersburg, 2011.
Korol' K.N., 2018. Credit behavior of modern youth in Russia. Vestnik Saratovskogo gosudarstvennogo social'no-ehkonomicheskogo universiteta, no. 1 (70), pp. 144-146.

Credit behavior of Russians of different ages/ National credit histories Bureau. URL: https://www.nbki.ru/ upload/pdf/2013_06_14_kreditnoe_povedenie.pdf (accessed 1 September 2018).

Natitnik A. "The Debtors are easier to manage" (interview with the author of the study "Life in debt" G. B. Yudin).URL: https://hbr-russia.ru/ biznes-i-obshchestvo/fen omeny/778884 (accessed 15 September 2018).

Popova I.V., Dudina I.M., 2018. Axiological aspect of the credit behavior of young people (empirical research). CITISEH, no. 1 (14), p. 19.

Order of the Government of the Russian Federation of September 25, 2017 no. 2039-R on approval of the Strategy for improving financial literacy in the Russian Federation for 2017-2023. URL: http:/www.garant.ru/products/ipo/prime/doc/ 71675558/\#ixzz5NZ8nq1NU (accessed 15 September 2018).

Revzina S.L., 2010. Students' knowledge about credits and credit cards. Izvestiya Saratovskogo universiteta. Novaya seriya. Seriya: Sociologiya. Politologiya, Vol. 10, no. 2, pp. 46-48.

Information on placed and raised funds. Official website of the Central Bank of the Russian Federation. URL: http://www.cbr.ru/statistics/?PrtId=sors (accessed 10 September 2018).

Promotion of financial literacy of the population and development of financial education in the Russian Federation. Information of the official website of the Ministry of Finance of the Russian Federation. URL: https://www.minfin.ru/ru/om/ fingram/news/\#ixzz5NZ6ZVgcP (accessed 15 September 2018).

Solov'eva O. Russians don't like credits, but they can't live without them. URL: http://www.ng.ru/ economics/2018-09-30/4_7321_credit.html (accessed 15 September 2018).

Strebkov D.O., 2004. The main types and factors of credit behavior of the population in modern Russia. Voprosy ehkonomiki, no. 2, pp. 109-128.

Strebkov D.O., 2007. Models of credit behavior and factors determining their choice. Sociologicheskie issledovaniya, no. 3 (275), pp. 52-62.

Strebkov D.O., 2007. Social aspects of credit behavior. Sociologicheskij zhurnal, no. 1, pp. 83-103.

Strebkov D.O., Gribova E.A. Development of lending system in Russia: analysis of needs and preferences of the population. URL: http:// www.socpol.ru/grantprog/pdf/Strebkov.pdf (accessed 1 September 2018). 
Fatihov A.I., Nasibullin R.T., 2010. Problems of formation of financial culture of the population of Russia through the prism of sociological research. Vestnik TOGU, no. 2 (7), pp. 235-244.

Fomchenkov T. Let's Take, youth! The number of loans for young people is growing faster than for people of other ages. URL: https://rg.ru/2017/ 04/23/issledovanie-molodye-liudi-chashchedrugih-berut-kredity.html (accessed 1 September 2018).

Yudin G.B., 2015. The Moral nature of debt and develop a responsible borrower. Voprosy ehkonomiki, no. 3, pp. 28-45.

Adzis, A.A., Bakar, J.A., Shahar, H.K., 2017. Factors influencing young adults' debt in Malaysia. Journal of Business and Retail Management Research, no. 12 (1), pp. 76-85.

Bosshardt W., Walstad W.B., 2018. Does studying economics in college influence loan decisions later in life? Journal of Economic Education, no. 49 (2), pp. 130-141. DOI: 10.1080/00220485. 2018.1438948.

Darolia, R., Harper, C., 2018. Information Use and Attention Deferment in College Student Loan Decisions: Evidence From a Debt Letter Experiment.Educational Evaluation and Policy Analysis, no. 40 (1), pp. 129-150. DOI: 10.3102/ 0162373717734368.

Elliott W., Lewis M., 2015. Student debt effects on financial well-being: Research and policy implications. Journal of Economic Surveys, no. 29 (4), pp. 614-636. DOI: 10.1111/joes.12124.

Min S., Taylor M.G., 2018. Racial and Ethnic Variation in the Relationship Between Student Loan Debt and the Transition to First Birth. Demography, no. 55 (1), pp. 165-188. DOI: 10.1007/s13524-0170643-6 10.3102/0162373717709968.
Norvilitis J.M., 2014. Changes over time in college student credit card attitudes and debt: evidence from one campus. The Journal of consumer affairs, Vol. 48, no. 3, pp. 634-647.

Norvilitis J.M., Mao Y., 2013. Attitudes towards credit and finances among college students in China and the United States. International Journal of Psychology, Vol. 48, no. 3, pp. 389-398.

Norvilitis, J. M., Merwin M.M., Osberg T.M., Roehling P.V., Young P., Kamas M. M., 2006. Personality Factors, Money Attitudes, Financial Knowledge, and Credit-Card Debt in College Students. Journal of Applied Social Psychology, Vol. 36, no. 6,pp. 1395-1413.

Perkins D., Johnston T., Lytle R., 2016. Addressing student debt in the classroom. Journal of Education for Business, no. 91 (3), pp. 117-124. DOI: 10.1080/08832323.2016.1140112.

Roberts. J.A., Jones E., 2001. Money Attitudes, Credit Card Use, and Compulsive Buying among American College Students. The Journal of Consumer Affairs, Vol. 35, no. 21, pp. 213-240.

Singh S., Rylander D.H., Mims T.C., 2016. College students and credit card companies: Implications of attitudes. Journal of Financial Services Marketing, no. 21 (3), pp. 182-193. DOI: 10.1057/ s41264-016-0007-0.

Williams A.J., Oumlil B., 2015. College student financial capability: A framework for public policy, research and managerial action for financial exclusion prevention. Marketing Intelligence and Planning, no. 33 (5), pp. 637-653. DOI: 10.1108/IJBM-06-2014-0081.

Wulandari D., 2016. Causes, effects and solutions of overspending behavior in university students. International Journal of Economic Research, no. 13 (7), pp. 3097-3110.

\section{Information about the Authors}

Nadezhda V. Dulina, Doctor of Sciences (Sociology), Professor, Department of Sociology, Volgograd State University, Prosp. Universitetsky, 100, 400062 Volgograd, Russian Federation, nvdulina@volsu.ru, https://orcid.org/0000-0002-6471-7073

Dar'ja V. Moiseeva, Candidate of Sciences (Sociology), Associate Professor, Department of the Management and Finance of Production Systems and Technological Entrepreneurship, Volgograd State Technical University, Prosp. Lenina, 28, 400005 Volgograd, Russian Federation, moiseeva-d@yandex.ru, https://orcid.org/0000-0003-2044-3418

Eugeniya V. Anufrieva, Candidate of Sciences (Philosophy), Associate Professor, Department of History, Culture and Sociology, Volgograd State Technical University, Prosp. Lenina, 28, 400005 Volgograd, Russian Federation, ev_anufrieva@mail.ru, https://orcid.org/0000-0002-0756-4488

Vera A. Paramonova, Candidate of Sciences (Sociology), Associate Professor, Department of Sociology, Volgograd State University, Prosp. Universitetsky, 100, 400062 Volgograd, Russian Federation, paramonova69@yandex.ru, https://orcid.org/0000-0001-6574-5597 


\section{СОЦИОЛОГИЯ И СОЦИАЛЬНЫЕ ТЕХНОЛОГИИ}

\section{Информация об авторах}

Надежда Васильевна Дулина, доктор социологических наук, профессор кафедры социологии, Волгоградский государственный университет, просп. Университетский, 100, 400062 г. Волгоград, Российская Федерация, nv-dulina@volsu.ru, https://orcid.org/0000-0002-6471-7073

Дарья Викторовна Моисеева, кандидат социологических наук, доцент кафедры менеджмента и финансов производственных систем и технологического предпринимательства, Волгоградский государственный технический университет, просп. Ленина, 28, 400005 г. Волгоград, Российская Федерация, moiseeva-d@yandex.ru, https://orcid.org/0000-0003-2044-3418

Евгения Владимировна Ануфриева, кандидат философских наук, доцент кафедры истории, культуры и социологии, Волгоградский государственный технический университет, просп. Ленина, 28, 400005 г. Волгоград, Российская Федерация, ev_anufrieva@mail.ru, https://orcid.org/00000002-0756-4488

Вера Александровна Парамонова, кандидат социологических наук, доцент кафедры социологии, Волгоградский государственный университет, просп. Университетский, 100, 400062 г. Волгоград, Российская Федерация, paramonova69@yandex.ru, https://orcid.org/0000-0001-6574-5597 